\title{
Bone mineral density in Australian children, adolescents and adults with cystic fibrosis: a controlled cross sectional study
}

\author{
H M Buntain, R M Greer, P J Schluter, J C H Wong, J A Batch, J M Potter, P J Lewindon, E Powell, \\ C E Wainwright, S C Bell
}

Thorax 2004;59:149-155. doi: 10.1136/thorax.2003.006726

See end of article for authors' affiliations

.....................

Correspondence to: Dr H M Buntain, Department of Respiratory Medicine, Royal Children's Hospital, Brisbane, Queensland 4051, Australia; scottmel@ bigpond.net.au

Received 21 March 2003 Accepted

24 September 2003

\begin{abstract}
Background: Low bone mineral density (BMD) is recognised in individuals with cystic fibrosis (CF) although the pathogenesis remains unclear. The aims of this study were to compare BMD over a broad continuum of Australian individuals with CF with healthy controls and to examine the relationship between BMD and clinical parameters including physical activity, nutrition, and vitamin D levels.

Methods: BMD of the lumbar spine (LS), total body (TB), femoral neck (FN), cortical wrist (R33\%), and distal wrist (RUD) was examined in 153 individuals with CF aged 5.3-55.8 years (84 males) and in 149 local controls aged 5.6-48.3 years (66 males) using dual energy $x$ ray absorptiometry. Anthropometric variables, body cell mass, markers of disease severity, corticosteroid usage, measures of physical activity, dietary calcium and caloric intake and serum vitamin $D$ were assessed and related to BMD.

Results: Compared with controls, mean BMD was not significantly different in children aged 5-10 years with CF. Adolescents (females 11-18 years, males 11-20 years) had reduced TB and R33\% BMD when adjusted for age, sex, and height (difference in $B M D\left(\mathrm{~g} / \mathrm{cm}^{2}\right)$ adjusted means between control and $\mathrm{CF}$ : $\mathrm{TB}=0.04(95 \% \mathrm{Cl} 0.01$ to 0.07$) ; \mathrm{R} 33 \%=0.03(95 \% \mathrm{Cl} 0.01$ to 0.06$)$ ). $\mathrm{BMD}$ was reduced at all sites except $\mathrm{R} 33 \%$ in adults (difference in $\mathrm{BMD}\left(\mathrm{g} / \mathrm{cm}^{2}\right.$ ) adjusted means between control and CF: TB $=0.05(95 \% \mathrm{Cl}$ 0.02 to 0.09 ); $\mathrm{LS}=0.08(95 \% \mathrm{Cl} 0.03$ to 0.14$) ; \mathrm{FN}=0.09$ (95\% Cl 0.03 to 0.15$) ; \mathrm{RUD}=0.03(95 \% \mathrm{Cl}$ 0.01 to 0.05$)$ ). In children/adolescents BMD was weakly associated with nutritional status and disease severity.

Conclusions: BMD was normal in a well nourished group of prepubertal children with CF. A BMD deficit appears to evolve during adolescence and becomes more marked in adults. Individuals with CF should optimise nutrition, partake in physical activity, and maximise lung health in order to optimise BMD. Further longitudinal studies are required to understand the evolution of reduced BMD in young people and adults with CF.
\end{abstract}

ow bone mineral density (BMD) in individuals with cystic fibrosis (CF) has previously been reported, ${ }^{1-5}$ although the -major factors contributing to the aetiology remain unclear. To date, few studies have been performed incorporating children, adolescents, and adults with CF to delineate the range and evolution of bone disease. Fracture incidence has been reported to increase during adolescence and adulthood in individuals with $\mathrm{CF}^{6-8} \mathrm{~A}$ fracture in an individual with CF may lead to reduced productivity, pain, and impedance of effective treatment directed at their suppurative lung disease. For these reasons it is important to establish the underlying pathogenesis and risk factors for low BMD in individuals with CF.

The potential factors contributing to low BMD include malnutrition, vitamin D deficiency, calcium malabsorption, pubertal delay, reduced physical activity, corticosteroid usage, chronic inflammation and, specifically in CF, a possible effect of the CF transmembrane conductance regulator on bone turnover. Vitamin D deficiency is rare in northern Australia because of high levels of sun exposure, so vitamin D supplementation in the CF population is not routine. As a consequence of lung disease, people with CF are thought to be less physically active than the general population, further contributing to the reduction in bone mass. The local climate and culture is conducive to outdoor activities and physical activity is encouraged for individuals with CF.

The aim of this study was to observe BMD over a continuum of an Australian CF population and to correlate BMD with many of the possible contributing factors, with special emphasis on physical activity, nutrition, and vitamin D status.

\section{METHODS}

\section{Subjects}

Patients with CF aged 5 years or older attending the Royal Children's Hospital (RCH) or the adult clinic at The Prince Charles Hospital (TPCH), Brisbane were invited to participate in this cross sectional study. Most paediatric patients transfer to adult care at TPCH. Patients who had a lung transplant or had a primary bone disease were excluded. The diagnosis of CF had been confirmed by a raised sweat chloride test. Healthy control subjects of a similar age and sex distribution to the CF cohort were recruited from local schools and friends of the CF participants and investigators. Exclusion criteria for control subjects included a chronic illness known to affect bone density or a period of immobility of more than 2 weeks in the preceding 12 months. Recruitment took place between March 2000 and December 2001. Each subject completed all study investigations within a 1 month period. The local ethics committees approved the study. Written informed consent was provided by all subjects aged 10 years or older and additionally by the legal guardian if the subject was aged less than 18 years.

\section{Bone densitometry measurements}

BMD of the total body (TB), lumbar spine (L2-4) (LS), femoral neck (FN), cortical radius (R33\%), and ultra distal 
radius (RUD) were measured using dual energy $x$ ray absorptiometry (DEXA) with a Lunar DPX-L bone densitometer (Madison, WI). The non-dominant forearm was used unless there had been a prior fracture in that arm. The departmental precision errors are $1 \%$ for the LS, TB, RUD and R33\% measurements and $1.5 \%$ for FN. BMD was expressed as $\mathrm{g} / \mathrm{cm}^{2}$. TB and LS BMD were also expressed as $Z$ scores and, in adults, TB, LS and FN were also expressed as $T$ scores using the Lunar normative database which has received contributions from several Australian sites. ${ }^{9}$

\section{Clinical measurements}

Weight and height were measured with calibrated electronic scales and a wall mounted stadiometer, respectively. Respiratory function tests were performed in accordance with the American Thoracic Society standards only in those with CF. The best recorded forced expiratory volume in 1 second $\left(\mathrm{FEV}_{1}\right)$ and forced vital capacity $(\mathrm{FVC})$ during the 6 months prior to and including the date of BMD assessment were recorded and expressed as percentage predicted..$^{111}$ Each patient self-assessed their pubertal status by comparing illustrations of pubertal development without parental influence. ${ }^{12}$ Age at menarche was recorded for females. Body cell mass (BCM) was measured by total body potassium. Using duplicate counts of 20 minutes, the device has an accuracy of $\pm 4 \%{ }^{13}$

\section{Dietary calcium intake and physical activity}

Using a standardised booklet, RCH subjects completed a 7 day food intake diary (as children can vary their diet substantially from day to day) and TPCH subjects completed a 3 day diary. Mean daily calcium and caloric intake was calculated using Foodworks Version 2.10.136 (Xyris Software (Australia) Pty Ltd). Each control subject's daily caloric intake was expressed as a percentage of the recommended daily caloric intake for Australian children and adults. ${ }^{14}$ For CF subjects, $120 \%$ of the recommended daily caloric intake was used in accordance with standard recommendations for CF care.

Individuals attending $\mathrm{RCH}$ completed the validated "Physical activity questionnaire for older children (9-15 years $)^{\prime \prime}{ }^{15}$ This is a self-administered 7 day recall questionnaire with nine items, each scored on a 5 point Likert scale and used to derive a total activity score. Adults attending TPCH were interviewed about their activity level and scored on a 5 point Likert scale. All subjects estimated the number of hours of their spare time spent partaking in physical activity and sedentary activity. Results were adjusted for location in the data analysis.

\section{Laboratory measurements}

Random non-fasting blood samples were collected. C reactive protein (CRP) was measured using latex enhanced immunonephelometry. 25-hydroxyvitamin D (25OHD) and 1,25dihydroxyvitamin $\mathrm{D}\left(1,25(\mathrm{OH})_{2} \mathrm{D}\right)$ were measured using DiaSorin RIA double antibody assay (DiaSorin, Stillwater, Minnesota, USA).

\section{Historical data}

The following data were collected by historical recall and/or chart review: (1) fracture events during the 2 years prior to the study, (2) pancreatic sufficiency status, (3) the presence of CF related liver disease (defined as the presence of multinodular cirrhosis and portal hypertension), and (4) the presence of CF related diabetes mellitus. The following information was collected for the 12 months prior to the study: (1) inhaled and oral corticosteroid usage, (2) number of chest exacerbations (defined as an increase in cough or sputum production sufficient to warrant change in antibiotic therapy), (3) number of admissions, and (4) total number of days in hospital. In view of the fact that fluticasone has greater potency, higher glucocorticoid receptor binding affinity, and a longer half life than beclomethasone and budesonide, ${ }^{16}$ the amount of fluticasone was doubled to be dose equivalent to beclomethasone. No adjustment was made to the budesonide dose. Inhaled and oral corticosteroid doses were expressed as the mean daily dose in $\mu \mathrm{g} / \mathrm{kg} / \mathrm{day}$ and $\mathrm{mg} /$ $\mathrm{kg} /$ day, respectively. Individuals with CF were classified according to their chronic Pseudomonas aeruginosa (PsA) colonisation status: (a) no PsA, (b) PsA for $<5$ years, and (c) PsA for $\geqslant 5$ years. The duration of PsA colonisation was also recorded for RCH subjects.

\section{Statistical analysis}

Bone mass increases in an almost linear fashion until it peaks around 18 years in females and 20 years in males, and is thereafter reasonably constant until middle age. ${ }^{17} 18$ Data were therefore analysed as two subgroups: children/adolescents (females $5-18$ years and males $5-20$ years) and adults (females $>18$ years and males $>20$ years). Accelerated bone acquisition occurs during the first few years of life and the pubertal growth spurt. ${ }^{17-19}$. In view of this, the children/ adolescent group was further subdivided into children (510 years, only including self-assessed Tanner stage $\leqslant 2$ ) and adolescents ( $\geqslant 11$ years). Categorical and continuous variables measuring patient characteristics were compared using Fisher's exact test and Student's $t$ test, respectively. As areal measures of BMD, such as the one we have used, are influenced by age, sex and height, ${ }^{20}$ generalised linear models (GLM) relating BMD between CF and control groups were adjusted for these measures throughout the analyses. Principal component analysis was used to derive a single composite score for BMD from the five measured sites for each subject. This statistical method is used to combine a number of correlated variables measuring a similar entity. ${ }^{21}$ Several clinical parameters known to influence BMD in those with CF were unavailable in the control group and so a secondary investigation was undertaken only in those with CF. In this investigation the LS and principal component BMD measures were related to clinically plausible contributors in GLM that was also adjusted for age and sex. All significant variables were included in a multivariate stepwise model with inclusion and exclusion parameters set at the $5 \%$ level and the most parsimonious model found. Data were analysed using SAS version 8.2. Mean and standard deviation (SD), standard error (SE), or 95\% confidence interval $(95 \%$ CI) were reported. Significance was set at a p value of $<0.05$.

\section{RESULTS}

One hundred and fifty three subjects with CF and 149 healthy subjects agreed to participate in the study. The characteristics of the participants are shown in tables 1 and 2 . The study cohort appeared representative of the general clinic population with mean weight, height, and lung function not significantly different between participants and non-participants (data not shown). Compared with control subjects, weight and height in adolescents and weight in adults with CF were significantly reduced, although there was no significant difference in children. Body cell mass was lower in children/adolescents with CF than in controls (table 3). The mean age for Tanner stages $1,2-3$, and 4-5 for each sex were similar in CF and control subjects (females $\mathrm{p}=0.39$, males $p=0.16)$. Menarchal status in female subjects of 10 years or more was available in $43(83 \%)$ and $58(85 \%)$ CF and control subjects, respectively. Menarche had occurred in 30 (70\%) females with CF and 45 (77\%) control subjects and the mean age at menarche was similar in the two groups 
Table 1 Characteristics of CF and control participants divided into three age groups (children, adolescents and adults)

\begin{tabular}{|c|c|c|c|}
\hline Patient characteristics & CF & Control & $\mathrm{p}$ value \\
\hline \multicolumn{4}{|l|}{ Children (5-10 years) } \\
\hline $\mathrm{N}$ & 40 & 32 & \\
\hline$F / M$ & $21 / 19$ & $18 / 14$ & 0.81 \\
\hline Weight $Z$ score & $0.02(0.97)$ & $0.28(1.09)$ & 0.29 \\
\hline Height $Z$ score & $-0.22(0.95)$ & $0.21(1.06)$ & 0.08 \\
\hline Best $\mathrm{FEV}_{1}$ in last 6 months (\% predicted) & $83.5(14.5)$ & & \\
\hline \multicolumn{4}{|l|}{ Adolescents* } \\
\hline $\mathrm{N}$ & 55 & 75 & \\
\hline$F / M$ & $20 / 35$ & $37 / 38$ & 0.16 \\
\hline Weight $Z$ score & $-0.74(0.95)$ & $0.24(0.81)$ & $<0.001$ \\
\hline Height $Z$ score & $-0.82(0.82)$ & $0.61(0.93)$ & $<0.001$ \\
\hline Best $\mathrm{FEV}_{1}$ in last 6 months (\% predicted) & $77.5(23.6)$ & & \\
\hline \multicolumn{4}{|l|}{ Adultst } \\
\hline $\mathrm{N}$ & 58 & 42 & \\
\hline$F / M$ & $28 / 30$ & $28 / 14$ & 0.10 \\
\hline Weight $Z$ score & $-0.37(0.95)$ & $0.01(0.75)$ & 0.04 \\
\hline Height $Z$ score & $-0.13(1.09)$ & $-0.18(0.78)$ & 0.81 \\
\hline Best $\mathrm{FEV}_{1}$ in last 6 months (\% predicted) & $56.6(20.1)$ & & \\
\hline
\end{tabular}

$(\mathrm{CF}=13.6 \quad(\mathrm{SE}=0.27) \quad$ years, $\quad$ control $=13.3 \quad(\mathrm{SE}=0.20)$ years, $\mathrm{p}=0.23$ ).

\section{Bone mineral density}

Compared with controls, mean LS and TB BMD Z scores were significantly lower in adolescents and adults with CF (table 4) and TB, LS and FN $T$ scores were lower in adults with CF (table 5). A $Z$ score of less than -2 at the LS or TB was present in 15 adolescents (27\%) and seven adults (12\%) with CF. By WHO criteria, ${ }^{22}$ eight adults (14.5\%) with CF have osteoporosis ( $T$ score less than -2.5 ).

In view of the significant height discrepancy between groups, BMD for each site was adjusted for age, sex, and height and the difference in the means between controls and subjects with CF for each age group was reported (table 6). BMD remained lower at all sites except the R33\% in adults with $\mathrm{CF}$, but in adolescents only $\mathrm{TB}$ and $\mathrm{R} 33 \%$ remained lower in the CF subjects than in controls. There was no significant difference in BMD in children. Correlation coefficients between BMD measurements at different sites were high, ranging from 0.68 to 0.92 . The first principal component, derived from a linear combination of all five BMD measures, accounted for $84 \%$ of the total variance.

\section{Vitamin D status}

Supplemental vitamin D in the form of a multivitamin was taken by 116 CF individuals in a mean (SD) daily dose of 4.9 (1.4) $\mu \mathrm{g} /$ day (194.7 (54.8) IU/day). 25OHD levels were available in 141 individuals with CF and 134 controls; there was no significant difference in 25OHD levels between CF and control subjects for either age group (table 3 ). Vitamin D

\begin{tabular}{|lc|}
\hline Table 2 CF specific features \\
\hline
\end{tabular}

deficiency $(25 \mathrm{OHD} \leqslant 25 \mathrm{nmol} / \mathrm{l})$ was present in seven subjects with $\mathrm{CF}(5 \%)$ and in one control subject, and vitamin D insufficiency (25OHD 25-50 nmol/l) was present in 35 subjects with CF $(25 \%)$ and 28 controls $(21 \%)$. $1,25(\mathrm{OH})_{2} \mathrm{D}$ levels were significantly lower in subjects with CF (table 3), as previously reported, ${ }^{23}$ and eight CF subjects had a $1,25(\mathrm{OH})_{2} \mathrm{D}$ level below the local reference range.

\section{Physical activity}

Physical activity, as assessed by questionnaire and the number of hours of activity, was significantly lower in adults with CF than in control subjects, but no significant difference was found in children/adolescents (table 3). LS BMD was higher in children and adolescents with CF who had completed the activity questionnaire than in those who had not $(\mathrm{p}=0.002)$.

\section{Dietary intake}

Dietary diaries were available for analysis in 88 subjects with CF (64\%) and 98 controls (66\%). There was no significant difference in BMD between those who had and those who had not completed the diaries (data not shown). The mean daily calcium intake for both groups was above the recommended minimum daily intake of $800 \mathrm{mg} .{ }^{14}$ Individuals with CF consumed significantly higher amounts of calcium and a higher percentage of the recommended caloric intake than control subjects (table 3 ).

\section{Corticosteroid exposure}

Inhaled corticosteroids were taken by 113 subjects with CF $(82 \%)$ and 12 controls ( $8 \%$ ) during the 12 months prior to their study date. Oral corticosteroids were taken by $43 \mathrm{CF}$ subjects $(31 \%)$ and by one control subject, although only eight CF subjects had taken oral corticosteroids for more than 90 days. Both inhaled and oral corticosteroid intake was higher in the CF cohort (table 3).

\section{Fracture incidence}

A fracture during the 2 years prior to the study was reported on 12 occasions in 11 subjects with CF $(8 \%)$ and on 13 occasions in $13(9 \%)$ control subjects, with the forearm being the most common site. For the entire study population R33\% BMD was significantly lower in those who had had a fracture $(p=0.03)$, but there was no significant difference when CF and control groups were examined independently. 
Table 3 Comparison of clinical measures in CF and control subjects divided into children/adolescent and adult groups

\begin{tabular}{|c|c|c|c|c|c|}
\hline \multirow[b]{2}{*}{ Clinical measures } & \multicolumn{2}{|l|}{ CF } & \multicolumn{2}{|c|}{ Control } & \multirow[b]{2}{*}{$\mathrm{p}$ value } \\
\hline & $\mathbf{N}$ & Mean (SE) & $\mathbf{N}$ & Mean (SE) & \\
\hline \multicolumn{6}{|l|}{ Children/adolescents* } \\
\hline Body cell mass (g) & 89 & $16.1(0.8)$ & 105 & $19.3(0.8)$ & 0.007 \\
\hline Calcium intake (g) & 49 & $1372(84)$ & 69 & $933(71)$ & $<0.001$ \\
\hline Difference from recommended caloric intake (\%) & 49 & $60.3(2.9)$ & 69 & $52.2(2.4)$ & 0.04 \\
\hline 25 -hydroxy vitamin $D(\mathrm{nmol} / \mathrm{l})$ & 93 & $60.9(1.7)$ & 93 & $64.9(1.7)$ & 0.09 \\
\hline 1, 25-hydroxy vitamin D (pmol/l) & 93 & $93.6(4.5)$ & 85 & $127.3(4.7)$ & $<0.001$ \\
\hline Inhaled corticosteroids ( $\mu \mathrm{g} / \mathrm{kg} /$ day) & 93 & $38.6(2.7)$ & 107 & $2.0(2.5)$ & $<0.001$ \\
\hline Oral corticosteroids (mg/kg/day) & 93 & $0.22(0.04)$ & 107 & $0.00(0.04)$ & $<0.001$ \\
\hline $\mathrm{CRP}(\mathrm{mg} / \mathrm{l})$ & 91 & $4.6(0.6)$ & 95 & $2.8(0.6)$ & 0.03 \\
\hline Activity questionnaire scoreł & 53 & $2.9(0.1)$ & 83 & $2.8(0.1)$ & 0.41 \\
\hline Hours of physical activity $\ddagger$ & 43 & $16.7(1.8)$ & 70 & $13.1(1.4)$ & 0.12 \\
\hline Ratio of physical/sedentary activity $\ddagger$ & 43 & $3.7(1.4)$ & 70 & $2.3(1.1)$ & 0.44 \\
\hline \multicolumn{6}{|l|}{ Adults $†$} \\
\hline Body cell mass (g) & 36 & $23.2(0.5)$ & 32 & $24.3(0.5)$ & 0.14 \\
\hline Calcium intake (g) & 39 & $1672(122)$ & 29 & $1083(142)$ & 0.003 \\
\hline Difference from recommended caloric intake (\%) & 139 & $65.4(2.8)$ & 29 & $50.8(3.2)$ & 0.001 \\
\hline 25 -hydroxy vitamin $D(\mathrm{nmol} / \mathrm{l})$ & 48 & $54.7(2.9)$ & 41 & $59.6(3.2)$ & 0.26 \\
\hline 1, 25-hydroxy vitamin D (pmol/l) & 44 & $91.6(7.5)$ & 39 & $114.0(8.0)$ & 0.05 \\
\hline Inhaled corticosteroids ( $\mu \mathrm{g} / \mathrm{kg} /$ day) & 45 & $43.9(5.3)$ & 42 & $0.06(5.2)$ & $<0.001$ \\
\hline Oral corticosteroids (mg/kg/day) & 45 & $0.24(0.05)$ & 42 & $0.01(0.05)$ & $<0.001$ \\
\hline CRP (mg/l) & 49 & $11.5(1.4)$ & 42 & $2.9(1.5)$ & $<0.001$ \\
\hline Activity questionnaire scoreł & 41 & $3.2(0.1)$ & 38 & $3.7(0.1)$ & 0.005 \\
\hline Hours of physical activity $\ddagger$ & 38 & $30.6(4.1)$ & 38 & $53.2(4.1)$ & $<0.001$ \\
\hline Ratio of physical/sedentary activity $\ddagger$ & 38 & $6.6(2.3)$ & 38 & $8.9(2.3)$ & 0.48 \\
\hline
\end{tabular}

\section{Associations with BMD in individuals with CF}

In children/adolescents with CF there were significant positive univariate associations between principal component BMD and BMI, BCM, activity questionnaire score, weight, height, $\mathrm{FEV}_{1}, \mathrm{FVC}$, and the physical/sedentary activity ratio, and negative associations with inhaled corticosteroid intake, number of days in hospital, and CRP. In the final multivariate model BMI, BCM, and $\mathrm{FEV}_{1}$ were predictive of principal component BMD. Univariate analysis of the LS BMD found associations with the same measures except for inhaled corticosteroids. In addition, the number of admissions and the number of exacerbations were negatively associated and hours of physical activity was positively associated with LS $\mathrm{BMD}$. In the final multivariate model BCM, number of days in hospital, BMI, and number of hospital admissions were predictive of LS BMD (table 7). The contribution of age and sex was high (LS: $r^{2}=0.60$, principal component: $r^{2}=0.66$ ).

In adults with $\mathrm{CF}$, principal component $\mathrm{BMD}$ was significantly associated with BMI, BCM, weight, $\mathrm{FEV}_{1}, \mathrm{FVC}$, and the activity questionnaire score, while LS BMD was associated with the activity questionnaire score, physical/ sedentary activity ratio, number of admissions, number of days in hospital, weight, and BMI. In the final multivariate model for adults with CF, BCM and the number of days in hospital were predictive of principal component BMD and the activity questionnaire score was the only predictor of LS BMD. The contribution of age and sex were smaller (LS: $r^{2}=0.03$, principal component: $r^{2}=0.36$ ).

No association was found between BMD at any site and PsA status, duration of PsA colonisation, CF genotype, liver disease, diabetes, or pancreatic sufficiency status $(p>0.05)$.

\section{DISCUSSION}

This is the largest controlled study of BMD in individuals with CF across a continuum of ages reported to date and was performed in a Mediterranean environment, conducive of an "out of doors" lifestyle with increased opportunities for physical activity and increased sunlight exposure. This study found normal BMD in children with $\mathrm{CF}$, lower BMD at some sites in adolescents, and a significant BMD deficit in adults compared with local healthy controls in the setting of vitamin D sufficiency. We have also highlighted the importance of adjusting BMD for short stature. Local healthy subjects were used to control for greater nutritional health in Australian children over the last $\operatorname{decade}^{24}$ and to provide local

Table 4 Comparison of mean bone mineral density $Z$ scores between controls and subjects with CF and difference in mean values (with $95 \% \mathrm{Cl}$ ) in the three age groups (children, adolescents and adults)

\begin{tabular}{|c|c|c|c|c|c|c|c|c|c|}
\hline & \multicolumn{3}{|c|}{ Children } & \multicolumn{3}{|c|}{ Adolescents } & \multicolumn{3}{|c|}{ Adults } \\
\hline & $\mathbf{N}$ & Mean (SE) & $p$ value & $\mathbf{N}$ & Mean (SE) & p value & $\mathbf{N}$ & Mean (SE) & $p$ value \\
\hline \multicolumn{10}{|l|}{ Total body } \\
\hline Control & 32 & $0.26(0.12)$ & 0.87 & 75 & $0.36(0.11)$ & $<0.001$ & 41 & $0.34(0.13)$ & 0.003 \\
\hline $\mathrm{CF}$ & 40 & $0.23(0.12)$ & & 55 & $-0.51(0.17)$ & & 57 & $-0.23(0.12)$ & \\
\hline Difference* & & $0.03(-0.31$ to 0.37$)$ & & & 0.8710 .49 tc & & & $0.57(0.20$ to 0.93$)$ & \\
\hline \multicolumn{10}{|l|}{ Lumbar spine } \\
\hline Control & 32 & $-0.31(0.18)$ & 0.88 & 75 & $-0.21(0.20)$ & $<0.001$ & 42 & $-0.11(0.15)$ & 0.01 \\
\hline & 40 & $-0.28(0.15)$ & & 55 & $-1.26(0.11)$ & & 58 & $-0.67(0.15)$ & \\
\hline Difference* & & $-0.03(-0.49$ to 0.42$)$ & & & $1.05(0.58$ tc & & & $0.56(0.12$ to 1.00$)$ & \\
\hline
\end{tabular}

*Difference in means calculated by (control - CF) with $95 \% \mathrm{Cl}$. 
Table 5 Comparison of mean bone mineral density $T$ scores between adult controls and subjects with CF and difference in mean values (with 95\% Cl)

\begin{tabular}{|c|c|c|c|}
\hline & $\mathrm{N}$ & Mean (SE) & p value \\
\hline \multicolumn{4}{|l|}{ Total body } \\
\hline Control & 38 & $-0.01(0.16)$ & \multirow[t]{3}{*}{0.006} \\
\hline CF & 54 & $-0.60(0.13)$ & \\
\hline Difference* & & 0.59 (0.18 to 1.00 ) & \\
\hline \multicolumn{4}{|l|}{ Lumbar spine } \\
\hline Control & 39 & $-0.32(0.16)$ & \multirow[t]{3}{*}{0.009} \\
\hline CF & 55 & $-0.93(0.16)$ & \\
\hline Difference* & & $0.62(0.16$ to 1.08$)$ & \\
\hline \multicolumn{4}{|l|}{ Femoral neck } \\
\hline Control & 39 & $0.04(0.18)$ & \multirow[t]{3}{*}{0.003} \\
\hline $\mathrm{CF}$ & 55 & $-0.62(0.17)$ & \\
\hline Difference* & & $0.67(0.17$ to 1.16$)$ & \\
\hline
\end{tabular}

$T$ scores only available for those aged $\geqslant 20$ years.

*Difference in means calculated by (control - CF).

comparisons for dietary intake, physical activity, vitamin D, corticosteroid usage, and fracture occurrence.

The role of vitamin D in the pathogenesis of osteoporosis in CF remains unclear. Several studies have reported low serum 25OHD in individuals with $\mathrm{CF}_{1}^{13782526}$ and most report a lack of association between BMD and 25OHD. ${ }^{135}$ In this study 25OHD values were comparable in those with CF and the local controls, implying adequate vitamin D status, with mean values considerably higher than in other recent large studies. ${ }^{17}$ Despite this, we observed a significant BMD deficit in the presence of vitamin D sufficiency, further supporting the findings of abnormal bone histomorphology not consistent with osteomalacia in CF individuals. ${ }^{27} 28$

Low BMD in adolescents and adults with CF has been well documented ${ }^{155}$ and is supported by biochemical evidence of bone resorption and accretion imbalance. ${ }^{23} 29$ Normal BMD and nutritional status with functionally mild lung disease in the children, in conjunction with normal bone turnover, ${ }^{23}$ suggests normal bone growth at this early phase of life in our cohort. Our findings in this age group are supported by several other smaller studies. ${ }^{25}$ 30-32

The measurement of BMD in children and adolescents is problematic because of variable periods of growth. Short stature is associated with smaller bones and reduced bone surface area which contribute to a lower areal BMD. Bone mineral apparent density (BMAD) is a calculation made from areal BMD to adjust for bone volume. This method makes two assumptions: (1) the three dimensional shape of the bone and (2) the consistency of bone shape with growth. In view of the large age range in this study and the absence of anterior-posterior measures of the LS, we elected not to calculate BMAD but rather to adjust BMD for height.

The influence of height on BMD in individuals with CF has been clearly shown by Hardin and colleagues. ${ }^{31}$ They reported normal BMD in children and adults with CF compared with controls matched for age, sex, height, and lean tissue mass. In our study height greatly influenced BMD in the adolescent cohort. Not surprisingly, height did not influence BMD in adults in whom no significant difference in height was observed. Haworth and colleagues ${ }^{1}$ reported a smaller LS BMD deficit in individuals with CF when BMD was measured by quantitative CT scanning (a volumetric measure) compared with DEXA, further supporting the need to adjusted areal measures of BMD for height.

Comparison of BMD between studies is difficult because of the different methods of reporting. The mean BMD deficit in this study, as reported by $Z$ and $T$ scores in adults with CF, is less than that reported by other large studies. ${ }^{157}$ Less severe lung disease $\left(\mathrm{FEV}_{1}\right)$ or greater nutritional status (BMI) in our study does not account for this. It is also important to note that two of these studies ${ }^{15}$ included adolescents with CF and neither adjusted BMD for height. The use of areal BMD $Z$ scores to define osteoporosis and osteopenia in those with CF may overestimate the BMD deficit, particularly in adolescents, as there is no adjustment for height.

Disease severity and nutritional status, as indicated by weight, BMI, $\mathrm{FEV}_{\mathrm{l}}$, and Shwachman score, have repeatedly been shown in longitudinal ${ }^{326}$ and cross sectional ${ }^{1245733}$

Table 6 Comparison of mean bone mineral density (in $\mathrm{g} / \mathrm{cm}^{2}$ ) adjusted for age, sex, and height in controls and subjects with CF and difference in adjusted mean values (with $95 \% \mathrm{Cl}$ ) in the three age groups (children, adolescents, and adults)

\begin{tabular}{|c|c|c|c|c|c|c|c|c|c|}
\hline & \multicolumn{3}{|c|}{ Children } & \multicolumn{3}{|c|}{ Adolescents } & \multicolumn{3}{|c|}{ Adults } \\
\hline & $\mathbf{N}$ & Mean (SE) & $p$ value & $\mathbf{N}$ & Mean (SE) & $p$ value & $N$ & Mean (SE) & $p$ value \\
\hline \multicolumn{10}{|l|}{ Total body } \\
\hline Control & 32 & $0.85(0.01)$ & 0.65 & 75 & $1.05(0.01)$ & 0.03 & 41 & $1.17(0.01)$ & 0.002 \\
\hline $\mathrm{CF}$ & 40 & $0.86(0.01)$ & & 55 & $1.01(0.01)$ & & 57 & $1.11(0.01)$ & \\
\hline Difference* & \multicolumn{3}{|c|}{$-0.01(-0.03$ to 0.02$)$} & \multicolumn{3}{|c|}{0.04 (0.01 to 0.07$)$} & \multicolumn{3}{|c|}{$0.05(0.02$ to 0.09$)$} \\
\hline \multicolumn{10}{|l|}{ Lumbar spine } \\
\hline Control & 32 & $0.67(0.02)$ & 0.31 & 75 & $0.97(0.01)$ & 0.14 & 42 & $1.18(0.02)$ & 0.003 \\
\hline $\mathrm{CF}$ & 40 & $0.69(0.01)$ & & 55 & $0.93(0.02)$ & & \multirow[t]{2}{*}{58} & $1.10(0.02)$ & \\
\hline Difference $^{*}$ & \multicolumn{3}{|c|}{$-0.02(-0.06$ to 0.02$)$} & \multicolumn{3}{|c|}{$0.04(-0.01$ to 0.08$)$} & & $0.08(0.03$ to 0.14$)$ & \\
\hline \multicolumn{10}{|l|}{ Femoral neck } \\
\hline Control & 32 & $0.72(0.02)$ & \multirow[t]{3}{*}{0.79} & 75 & $0.99(0.02)$ & \multirow[t]{3}{*}{0.07} & 42 & $1.03(0.02)$ & \multirow[t]{3}{*}{0.002} \\
\hline $\mathrm{CF}$ & 37 & $0.71(0.02)$ & & 47 & $0.94(0.02)$ & & 58 & $0.94(0.02)$ & \\
\hline Difference* $^{*}$ & & $0.01(-0.05$ to 0.07$)$ & & & $0.05(0.00$ to 0.11$)$ & & & $0.09(0.03$ to 0.15$)$ & \\
\hline \multicolumn{10}{|c|}{ Ultra distal radius } \\
\hline Control & 32 & $0.25(0.01)$ & \multirow[t]{3}{*}{0.86} & 74 & $0.33(0.01)$ & \multirow[t]{3}{*}{0.12} & 41 & $0.38(0.01)$ & \multirow[t]{3}{*}{0.009} \\
\hline $\mathrm{CF}$ & 36 & $0.24(0.01)$ & & 46 & $0.30(0.01)$ & & 57 & $0.35(0.01)$ & \\
\hline Difference* $^{*}$ & & $0.00(-0.02$ to 0.02$)$ & & & $0.02(0.00$ to 0.05$)$ & & & $0.03(0.01$ to 0.05$)$ & \\
\hline \multicolumn{10}{|l|}{ Cortical radius } \\
\hline Control & 32 & $0.44(0.01)$ & \multirow[t]{3}{*}{0.75} & 74 & $0.61(0.01)$ & \multirow[t]{3}{*}{0.01} & 41 & $0.72(0.01)$ & \multirow[t]{3}{*}{0.07} \\
\hline $\mathrm{CF}$ & 36 & $0.44(0.01)$ & & 46 & $0.58(0.01)$ & & 57 & $0.70(0.01)$ & \\
\hline Difference ${ }^{*}$ & & $0.00(-0.02$ to 0.02$)$ & & & $0.03(0.01$ to 0.06$)$ & & & $0.02(0.00$ to 0.04$)$ & \\
\hline \multicolumn{10}{|c|}{ Principal component } \\
\hline Control & 32 & $-2.49(0.13)$ & \multirow[t]{3}{*}{0.82} & 74 & $0.37(0.13)$ & \multirow[t]{3}{*}{0.07} & 41 & $1.91(0.17)$ & \multirow[t]{3}{*}{0.001} \\
\hline CF & 36 & $-2.45(0.13)$ & & 46 & $-0.08(0.18)$ & & 57 & $1.16(0.14)$ & \\
\hline Difference* $^{*}$ & & $-0.04(-0.41$ to 0.32$)$ & & & $0.45(0.02$ to 0.88$)$ & & & $0.74(0.31$ to 1.18$)$ & \\
\hline
\end{tabular}




\begin{tabular}{|c|c|c|c|c|c|}
\hline & \multicolumn{2}{|c|}{ Overall } & \multirow[b]{2}{*}{ Variable* } & \multirow{2}{*}{$\begin{array}{l}\text { Parameter } \\
\text { estimates }\end{array}$} & \multirow[b]{2}{*}{$(95 \% \mathrm{Cl})$} \\
\hline & $\mathrm{N}$ & $r^{2}$ & & & \\
\hline \multirow{2}{*}{$\begin{array}{l}\text { Children/adolescents } † \\
\text { Lumbar spine }\end{array}$} & & & & & \\
\hline & 85 & 0.78 & $\begin{array}{l}\text { Body cell mass } \\
\text { No of days in hospital } \\
\text { BMI } \\
\text { No of hospital admissions }\end{array}$ & $\begin{array}{c}0.02 \\
-0.002 \\
0.01 \\
0.02\end{array}$ & $\begin{array}{l}(0.01 \text { to } 0.02) \\
(-0.004 \text { to }-0.001) \\
(0.00 \text { to } 0.02) \\
(0.00 \text { to } 0.04)\end{array}$ \\
\hline \multirow[t]{2}{*}{ Principal component } & 74 & 0.85 & BMI & 0.13 & $(0.05$ to 0.21$)$ \\
\hline & & & $\begin{array}{l}\text { Body cell mass } \\
\text { FEV }\end{array}$ & $\begin{array}{l}0.15 \\
0.01\end{array}$ & $\begin{array}{l}(0.08 \text { to } 0.22) \\
(0.00 \text { to } 0.02)\end{array}$ \\
\hline \multicolumn{6}{|l|}{ Adults $\ddagger$} \\
\hline Lumbar spine & 32 & 0.28 & Activity questionnaire score & 0.09 & $(0.03$ to 0.14$)$ \\
\hline \multirow[t]{2}{*}{ Principal component } & 32 & 0.62 & Body cell mass & 0.14 & $(0.06$ to 0.22$)$ \\
\hline & & & No of days in hospital & 0.01 & (0.00 to 0.02$)$ \\
\hline $\begin{array}{l}\text { BMI = body mass index; } \\
{ }^{*} \text { After adjusting for age } \\
\text { †Defined as } 5-18 \text { year } \\
\text { †Defined as }>18 \text { years }\end{array}$ & 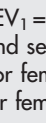 & 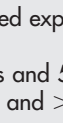 & $\begin{array}{l}\text { tory volume in } 1 \text { second. } \\
20 \text { years for males. } \\
0 \text { years for males. }\end{array}$ & & \\
\hline
\end{tabular}

studies to be weakly associated with BMD. Our findings are consistent with these previous reports. We did not find evidence of delayed puberty to support this as a contributor to low bone mass accrual.

Weight bearing activity has a positive influence on bone mass accrual and maintenance at all ages in healthy subjects. $^{34}{ }^{35}$ In this study we have used a validated physical activity questionnaire which has been shown to be associated with BMD in healthy children and adolescents. ${ }^{34}$ In children and adolescents, both controls and those with CF had similar mean activity levels and an association between BMD and physical activity was observed. The physical activity score was not a significant variable in the multivariate model for BMD, most probably because of the relationship between disease severity and physical activity. In adults with CF physical activity was significantly lower and did correlate with BMD, in agreement with the literature. ${ }^{157}$ Interestingly, the physical activity level was more predictive of BMD than other markers of disease severity in adults with CF.

Oral corticosteroids are well known to impede bone formation. This was not observed in our study and probably reflects the small number of subjects receiving long term corticosteroid treatment. In children/adolescents the use of inhaled corticosteroids was associated with a lower principal component BMD. Inhaled corticosteroids in children and adolescents with asthma appear to have a negligible effect on bone mass accrual and final adult height. ${ }^{3637}$ The growing bones of CF individuals may be more "at risk" of the effects of inhaled corticosteroids and further studies of the long term effects of inhaled corticosteroids are required.

The main clinical implication of low BMD in CF is the increased risk of limb and spinal fractures. In population studies an LS $Z$ score of less than -2 implies that an individual has a 4-6-fold increased risk of sustaining a fracture. ${ }^{38-40}$ There was no significant difference in the incidence of fractures in our study, which may reflect participation bias on behalf of the controls. Unfortunately, local fracture incidence data are not available for comparison.

The issue of timing of screening for bone disease in individuals with CF remains controversial. ${ }^{41}$ In view of the important influence of height on BMD highlighted in this study and the potent influence of puberty on growth and bone mass accrual, we recommend that BMD assessment should be performed after peak height is obtained. If BMD is measured earlier, an individual's height must be considered or volumetric measures used.
One of the major strengths of this study is that local controls were used for comparing BMD, clinical measures, dietary intake, physical activity, vitamin D, corticosteroid usage, and fracture occurrence, enabling a direct comparison of factors that may influence BMD. This study demonstrates the importance of adjustment for height in comparing BMD between groups, and it is one of the largest cohorts of patients with CF over a broad continuum of ages in which BMD has been studied. The limitations of the study include non-random selection of participants, reliance on historical recall for some of the clinical factors, and the limited available objective data for dietary intake and markers of physical activity.

As survival improves for individuals with $\mathrm{CF}$, the long term complications of the disease will become increasingly important. A better understanding of the factors that determine BMD during life in those with CF will be critical to enable preventive and treatment strategies to be developed and incorporated into routine care. BMD was normal in CF individuals before the onset of puberty in a well nourished population with preserved lung function. However, low BMD was identified in adolescents and adults with CF, despite the fact that the majority had vitamin $\mathrm{D}$ sufficiency. In agreement with previous studies, the associations found between BMD and clinical parameters only partially explain the observed reduction in BMD. This study highlights the importance of adjusting BMD for height, particularly in the presence of a significant height discrepancy in the study population. Our study supports the advice that children, adolescents, and adults with CF should maintain optimal nutritional status, partake in physical activity, minimise corticosteroid usage, and maximise lung health in order to optimise BMD. Further longitudinal studies are required to better understand the worrying deficit in bone health in young people and adults.

\section{ACKNOWLEDGEMENTS}

The first two authors contributed equally to this paper. The authors would like to thank Karen Cassidy, Alexia Murphy and Marita Pattimore for assisting in sample collection and body composition assessments and the staff involved with bone densitometry for flexible scheduling. Sincere thanks also to the patients and their families, the volunteer control subjects, and the staff of the Royal Children's Hospital and The Prince Charles Hospital Cystic Fibrosis Clinics. The study was supported by Cystic Fibrosis Research Australia Pty Ltd and the Royal Children's Hospital Foundation. 


\section{Authors' affiliations}

H M Buntain, C E Wainwright, Department of Respiratory Medicine,

Royal Children's Hospital, Herston, QLD 4029, Australia

R M Greer, Department of Paediatrics and Child Health, University of Queensland, Herston, QLD 4006, Australia

J C H Wong, Department of Nuclear Medicine \& Bone Densitometry, Royal Brisbane Hospital, QLD 4029, Australia

P J Schluter, School of Population Health, University of Queensland, Herston, QLD 4006, Australia

E Powell, Department of Dietetics, Royal Children' Hospital, Herston, QLD 4029, Australia

J M Potter, Department of Chemical Pathology, Queensland Health Pathology Service, Royal Brisbane Hospital, Herston, QLD 4029, Australia

J A Batch, Department of Endocrinology, Royal Children' Hospital, Herston, QLD 4029, Australia

P J Lewindon, Department of Gastroenterology and Hepatology, Royal Children's Hospital, Herston, QLD 4029, Australia

S C Bell, Adult CF Clinic, The Prince Charles Hospital, Chermside, QLD 4032, Australia

\section{REFERENCES}

1 Haworth CS, Selby PL, Webb ME, et al. Low bone mineral density in adults with cystic fibrosis. Thorax 1999;54:961-7.

2 Henderson RC, Madsen CD. Bone density in children and adolescents with cystic fibrosis. J Pediatr 1996;128:28-34

3 Bhudhikanok GS, Wang MC, Marcus R, et al. Bone acquisition and loss in children and adults with cystic fibrosis: a longitudinal study. J Pediatr 1998;133:18-27.

4 Laursen EM, Molgaard C, Michaelsen KF, et al. Bone mineral status in 134 patients with cystic fibrosis. Arch Dis Child 1999;81:235-40.

5 Conway SP, Morton AM, Oldroyd B, et al. Osteoporosis and osteopenia in adults and adolescents with cystic fibrosis: prevalence and associated factors. Thorax 2000; 55:798-804.

6 Henderson RC, Specter BB. Kyphosis and fractures in children and young adults with cystic fibrosis. J Pediatr 1994;125:208-12.

7 Elkin SL, Fairney A, Burnett S, et al. Vertebral deformities and low bone mineral density in adults with cystic fibrosis: a cross-sectional study. Osteoporos Int 2001; 12:366-72.

8 Aris RM, Renner JB, Winders AD, et al. Increased rate of fractures and severe kyphosis: sequelae of living into adulthood with cystic fibrosis. Ann Intern Med 1998;128:186-93.

9 Lu PW, Cowell CT, LLoyd-Jones SA, et al. Volumetric bone mineral density in normal subjects, aged 5-27 years. J Clin Endocrinol Metab 1996;81:1586-90.

10 Hibbert ME, Lannigan A, Landau LI, et al. Lung function values from a longitudinal study of healthy children and adolescents. Pediatr Pulmonol 1989;7:101-9

11 Morris JF, Koski A, Johnson LC. Spirometric standards for healthy nonsmoking adults. Am Rev Respir Dis 1971;103:57-67.

12 Tanner JM. Growth at adolescence. Oxford: Blackwell Scientific Publications, 1962:28-39.

13 Cohn SH, Dombrowski CS. Absolute measurement of whole-body potassium by gamma-ray spectrometry. J Nucl Med 1970;1 1:239-46.

14 NHMRC. Recommended dietary intakes for use in Australia. Australia: Commonwealth of Australia, 1998.

15 Crocker PR, Bailey DA, Faulkner RA, et al. Measuring general levels of physical activity: preliminary evidence for the Physical Activity Questionnaire for Older Children. Med Sci Sports Exerc 1997;29:1344-9.
16 Adams N Bestall JM Jones PW. Fluticasone versus beclomethasone or budesonide for chronic asthma. Cochrane Database Syst Rev 2002:CD002310.

17 Bonjour JP, Theintz G, Buchs B, et al. Critical years and stages of puberty for spinal and femoral bone mass accumulation during adolescence. J Clin Endocrinol Metab 1991;73:555-63.

18 Lu PW, Briody JN, Ogle GD, et al. Bone mineral density of total body, spine, and femoral neck in children and young adults: a cross-sectional and longitudinal study. J Bone Miner Res 1994:9:1451-8.

19 Carrie Fassler AL, Bonjour JP. Osteoporosis as a pediatric problem. Pediatr Clin North Am 1995;42:811-24.

20 Carter DR, Bouxsein ML, Marcus R. New approaches for interpreting projected bone densitometry data. J Bone Miner Res 1992;7:137-45.

21 Gnanadesikan R. Methods for statistical data analysis of multivariate observations. New York: John Wiley \& Sons, 1977.

22 Kanis JA, Melton $\sqcup$, Christiansen C, et al. The diagnosis of osteoporosis. J Bone Miner Res 1994;9:1137-41.

23 Greer RM, Buntain HM, Potter JM, et al. Abnormalities of the PTH-vitamin D axis and bone turnover markers in children, adolescents and adults with cystic fibrosis: comparison with healthy controls. Osteoporos Int 2003;14:404-11.

24 Magarey AM, Daniels LA, Boulton TJ. Prevalence of overweight and obesity in Australian children and adolescents: reassessment of 1985 and 1995 data against new standard international definitions. Med J Aust 2001;174:561-4.

25 Mortensen LA, Chan GM, Alder SC, et al. Bone mineral status in prepubertal children with cystic fibrosis. J Pediatr 2000;136:648-52.

26 Haworth CS, Selby PL, Horrocks AW, et al. A prospective study of change in bone mineral density over one year in adults with cystic fibrosis. Thorax 2002:57:719-23

27 Haworth CS, Webb AK, Egan JJ, et al. Bone histomorphometry in adult patients with cystic fibrosis. Chest 2000;118:434-9.

28 Elkin SL, Vedi S, Bord S, et al. Histomorphometric analysis of bone biopsies from the iliac crest of adults with cystic fibrosis. Am J Respir Crit Care Med 2002; 166:1470-4

29 Baroncelli GI, De Luca F, Magazzu G, et al. Bone demineralization in cystic fibrosis: evidence of imbalance between bone formation and degradation. Pediatr Res 1997:41:397-403.

30 Haslam RH, Borovnicar DJ, Stroud DB, et al. Correlates of prepubertal bone mineral density in cystic fibrosis. Arch Dis Child 2001;85:166-71.

31 Hardin DS, Arumugam R, Seilheimer DK, et al. Normal bone mineral density in cystic fibrosis. Arch Dis Child 2001;84:363-8.

32 Salamoni $F$, Roulet $M$, Gudinchet $F$, et al. Bone mineral content in cystic fibrosis patients: correlation with fat-free mass. Arch Dis Child 1996;74:314-8.

33 Gibbens DT, Gilsanz V, Boechat MI, et al. Osteoporosis in cystic fibrosis. J Pediatr 1998;113:295-300.

34 Bailey DA. Physical activity and the attainment of peak bone mass in children. Aust J Sci Med Sport 1994;March/June:3-5.

35 Cooper C, Cawley M, Bhalla A, et al. Childhood growth, physical activity, and peak bone mass in women. J Bone Miner Res 1995;10:940-7.

36 Anon. Long-term effects of budesonide or nedocromil in children with asthma. The Childhood Asthma Management Program Research Group. N Engl J Med 2000;343: 1054-63.

37 Agertoft L, Pedersen S. Effect of long-term treatment with inhaled budesonide on adult height in children with asthma. N Engl J Med 2000;343:1064-9.

38 Kroger $\mathrm{H}$, Huopio J, Honkanen R, et al. Prediction of fracture risk using axial bone mineral density in a perimenopausal population: a prospective study. $J$ Bone Miner Res 1995; 10:302-6.

39 Jones IE, Taylor RW, Williams SM, et al. Four-year gain in bone mineral in girls with and without past forearm fractures: a DXA study. Dual energy $x$-ray absorptiometry. J Bone Miner Res 2002:17:1065-72

40 Goulding A, Jones IE, Taylor RW, et al. Bone mineral density and body composition in boys with distal forearm fractures: a dual-energy $\mathrm{x}$-ray absorptiometry study. J Pediatr 2001;139:509-15.

41 Joseph PM. Screening for CF bone disease. Pediatr Pulmonol 2002;34(Suppl 24):178-9. 